\title{
Linguagens e Educação Física na BNCC: uma análise a partir das habilidades prescritas
}

\author{
Languages and Physical Education at the BNCC: an analysis based on prescribed skills \\ Lenguajes y Educación Física en BNCC: un análisis basado en habilidades prescritas
}

\author{
Nathalia Dória Oliveira ${ }^{a}$ (D) Dandara Queiroga de Oliveira Sousab (iD, \\ Antonio Fernandes de Souza Junior ${ }^{c}$ (D) , Rayanne Medeiros da Silvad (D), \\ Allyson Carvalho de Araújo** (D)
}

\section{Palavras-chave}

BNCC;

Ensino fundamental;

Educação Física;

Linguagens.

\section{Keywords}

BNCC;

Elementary school; Physical Education; Languages.

\begin{abstract}
RESUMO
O texto tem como objetivo analisar como as habilidades prescritas ao ensino de Educação Física no Ensino Fundamental se articulam com as diferentes formas de linguagens. Para isto, optamos pela abordagem qualitativa com o tipo de pesquisa documental. Com a análise de conteúdo, recortamos as unidades de registros nos termos ou palavras que compõem cada categoria a priori com base na teoria dos multiletramentos: linguagem escrita, linguagem oral e as representações visuais, sonoras, táteis, gestuais, de si mesmo e espaciais. Em nossa análise, destacamos a limitada apreensão teórica da BNCC sobre a noção de linguagem na Educação Física que pouco explora as múltiplas linguagens, tanto ao longo dos anos escolares como nas unidades temáticas.
\end{abstract}

\begin{abstract}
The text aims to analyze how the skills prescribed to the teaching of Physical Education in Elementary Education is articulated with the different forms of languages. For this, we opted for the qualitative approach with the type of documentary research. With content analysis, we cut the units of records in terms or words that compose each category, at first, based on the theory of multi-tools: written language, oral language and visual, sound, tactile, gestural, self and spatial representations. In our analysis, we highlight the limited theoretical apprehension of BNCC on the notion of language in Physical Education that little explores the multiple languages, both over the school years and in the thematic units.
\end{abstract}

\begin{abstract}
RESUMEN
El texto tiene como objetivo analizar cómo las competencias prescritas a la enseñanza de la Educación Física en Educación Primaria se articulan con las diferentes formas de lenguajes. Para ello, optamos por el enfoque cualitativo con el tipo de investigación documental. Con el análisis de contenido, cortamos las unidades de registros en términos o palabras que componen cada categoría, a priori en base a la teoría de las multiherramientas: lenguaje escrito, lenguaje oral y representaciones visuales, sonoras, táctiles, gestuales, del self y espaciales. En nuestro análisis, destacamos la escasa aprehensión teórica del BNCC sobre la noción de lenguaje en Educación Física que explora poco los múltiples lenguajes, tanto a lo largo de los años escolares

como en las unidades temáticas.
\end{abstract}

Palabras-clave

Enseñanza

fundamental; Educación Física; Idiomas.

a Universidade Federal do Rio Grande do Norte. Natal, RN, Brasil.

bUniversidade do Estado do Rio Grande do Norte, Departamento de Educação Física. Pau dos Ferros, RN, Brasil.

'Universidade do Estado de Minas Gerais, Departamento de Corpo e Movimento Humano. Passos, MG, Brasil.

dSecretaria Estadual de Educação. Natal, RN, Brasil.

eUniversidade Federal do Rio Grande do Norte, Centro de Ciências de Saúde, Departamento de Educação Física, Programa de Pós graduação em Educação Física, Programa de Pós graduação em Educação. Natal, RN, Brasil.

\footnotetext{
*Autor correspondente:

Allyson Carvalho de Araújo

E-mail: allyssoncarvalho@hotmail.com 


\section{INTRODUÇÃO}

Os debates da Educação Física que aproximam a área ao campo teórico das linguagens é tributária da ampliação epistemológica deste componente curricular no Brasil a partir da década de 1990 (Kunz, 1991), mobilizando congruências entre os diferentes documentos que normatizam e direcionam as práticas curriculares no país, tais quais os Parâmetros Curriculares Nacionais (PCNs) e a Base Nacional Comum Curricular (BNCC), que reafirmam sua a presença na área das linguagens (Brasil, 1997, 2018).

No entanto, consideramos que a BNCC, por constituir um documento oficial de orientação curricular para o Brasil, carece de uma definição mais sólida a fim de justificar o pertencimento da Educação Física escolar na área de linguagem. Essa percepção corrobora com Neira (2018), ao apontar a fragilidade e insuficiente dedicação textual sobre os elementos conceituais que fundamentam a concepção de Educação Física presente no documento. Nesse sentido, para além de compreender as práticas corporais como "passíveis de leitura e produção" (Brasil, 2018, p. 214), precisamos avançar em relação às concepções que entendem as linguagens como um processo unicamente de escrita e oralidade.

Para embasar este debate, recorremos ao filósofo Merleau-Ponty que faz críticas às concepções clássicas, tal qual o empirismo que defende uma objetividade pura e apresenta o sujeito como inexistente, reduzindo a linguagem a um processo mecânico regido pelas leis fisiológicas ou psíquicas. Bem como a concepção do idealismo (intelectuais) que enaltece o sujeito e a subjetividade, e põe a linguagem como produto direto do pensamento (Merleau-Ponty, 1991). Assim, as concepções tradicionais não admitem a exterioridade entre o signo e significado; nesse sentido, a linguagem não tem valor expressivo e autonomia própria (Furlan e Bocchi, 2003).

Com isso, Merleau-Ponty rompe com essas concepções afirmando que a linguagem "[...] é por si oblíqua e autônoma e, se lhe acontece significar diretamente um pensamento ou uma coisa, trata-se apenas de um poder secundário, derivado da sua vida interior" (Merleau-Ponty, 1991, p. 45). Também é rompida a ideia de separação de corpo e alma, sujeito e objeto, tendo a visão do corpo humano habitado e animado por uma consciência, defendendo o existencialismo em que todo o conhecimento se limita ao mundo dos fenômenos, construído pela percepção e sensação, sendo esta particular, perfeita e incompleta.

Com isso, a linguagem não é um fenômeno acabado com técnicas e nem uma justaposição de signos, mas se dá pelo ato, no gesto, sendo indireta e se expressando pelo o que diz e o que não se diz das palavras, um processo contínuo que vai para além de um código, acontecendo à comunicação quando há continuação do outrem.
O corpo é, portanto, potência comunicativa, no qual "[...] a linguagem é pulsação de minhas relações com o outro [...]" (Nóbrega e Medeiros, 2009, p. 725). E é no bojo deste debate que as práticas corporais estão interligadas com a cultura, possibilitando a argumentação que sustenta a concepção de Educação Física como campo de saberes vinculados à área das linguagens.

Nesse campo, muitos pesquisadores e estudiosos vêm defendendo os multiletramentos em que os sujeitos são criadores de significados em que experimenta, conceitua, analisa e aplica as diversas linguagens e representações apreendidas e as transformam a partir do pensamento crítico.

Os multiletramentos, ao colocarem em primeiro plano a inter-relação entre diferentes modalidades de linguagem, lançam novos desafios ao ensino da leitura e da escrita. Mas se os multiletramentos, potencializados pelas convergências midiáticas das tecnologias digitais, anseiam se estabelecer como uma pedagogia da sinestesia, as leituras e as escritas precisam incorporar a capacidade de entrecruzar linguagens que não se esgotam no âmbito verbal. (Pereira, 2014, p. 65).

As literacias são, portanto, mais que habilidades cognitivas de alfabetização, enquadram-se práticas sociais dentro de cada contexto social, cultural, educacional e político. Uma concepção de multiliteracias compreende o acionamento de diferentes signos e significados de comunicação, que incluem as expressões visuais, táteis dentre outras possibilidades como as linguagens vinculadas as novas mídias (Rosa, 2016).

Nesse sentido e mobilizados pelos debates conceituais sobre a linguagem, em uma perspectiva de multiplicidades de letramentos, bem como a fragilidade argumentativa sobre a justificativa do componente curricular Educação Física estar presente na área do conhecimento das linguagens na BNCC, tivemos o objetivo de analisar como as habilidades prescritas ao trato didático-pedagógico da Educação Física no ensino fundamental se articulam com as diferentes formas de linguagens.

\section{METODOLOGIA}

Utilizamos a abordagem qualitativa (Minayo, 2007, p. 57) do tipo de pesquisa documental. Assim, o estudo se debruça no documento público da BNCC (etapa do Ensino Fundamental) e especificamente, na disciplina Educação Física que se encontra dentro da área de Linguagens.

A partir da análise de conteúdo (Bardin, 2011), foi feita a avaliação prévia com a leitura flutuante da parte específica do documento selecionado na pesquisa a fim de iniciar a sistematização das ideias para atingir o objetivo e direção do estudo. Em seguida, exploramos o material destacando as unidades de registro, do tipo palavra, descritas nas habilidades de ensino de cada ano e unidades temáticas de acordo com as categorias pré-estabelecidas por Cope e Kalantzis (2009, p. 178- 
179, tradução nossa): linguagem escrita, linguagem oral e as representações visuais, sonoras, táteis, gestuais, de si mesmo e espaciais. Assim como Pereira (2014, p. 45), assumimos as categorias acima elencadas, por compreender que a classificação proposta por Cope e Kalantzis (2009):

(1) assume a multimodalidade da linguagem ampliada pelas tecnologias digitais - como um dos seus elementos fundantes, explicitando o gestual (não apenas no entendimento restrito de gesto) como uma dessas modalidades; (2) afirma que os multiletramentos, ao entrecruzarem diferentes tipos de linguagem, seriam uma pedagogia da sinestesia.

Elucidamos que um dos autores iniciou a pré-análise destacando os termos/palavras que se constituíram nas unidades de registros. Em seguida, os demais autores fizeram a categorização das unidades e análise individual dos dados em consonância com a literatura. Ao fim, por meio de um diálogo coletivo, os dados foram confrontados e a partir disso foi realizada a síntese apresentada nesse trabalho.

No rastro dessa recorrência e conforme dialogado anteriormente no texto, estamos nos referendando em compreensões de linguagem que não se esgotam na perspectiva instrumental do uso ou numa visão hierarquizada que privilegia uma linguagem em detrimento de outra. No sentido oposto, buscamos perceber a ampliação das possibilidades de linguagem ou linguagens.

A seguir, na Figura 1, sintetizamos as categorias definidas a priori para análise à luz da teoria dos multiletramentos, seguidas de seus conceitos e por fim, os termos ou palavras que compõem cada categoria.

Por fim, a partir das categorias e unidades de registros, realizamos os tratamentos dos resultados e interpretação respaldados no referencial teórico que possibilita reflexões e debates sobre limites e possibilidades das linguagens dentro da Educação Física.

\section{RESULTADOS E DISCUSSÕES}

Os resultados levantados nessa pesquisa se dão a partir das categorias de análise apresentadas e descritas na Figura 1. Através delas, discutiremos a problemática anunciada, acionando o referencial sobre as múltiplas linguagens e seus diálogos com os anos da etapa de ensino fundamental da BNCC e as unidades temáticas propostas.

O exercício de leitura flutuante, seguido da composição de nosso corpus de análise, na fase prévia, se deu de forma manual. Para isso, atribuímos cores para as diferentes unidades de registro que foram expressas ao longo do documento.

Nesse primeiro exercício, constatamos inicialmente e com uma observação amplificada na perspectiva imagética, que havia maior multiplicidade de linguagem destinada aos anos iniciais, o que, na linguagem textual, se materializa como mais categorias (aqui trazidas como linguagem e/ou representações), conforme também podemos perceber nas Figuras conseguintes. Com o passar dos anos percebe-se cada vez menos linguagens ou representações sendo preconizadas. Procedendo a análise mais detalhada, trazemos alguns pontos importantes à reflexão.

Há por duas vezes expresso no documento a citação do termo "múltiplas linguagens" - nos conteúdos

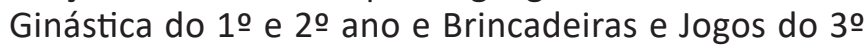
a 5ㅇ ano - e, após eles, um detalhamento do que isso seria. Então, aparecem os termos "corporal, oral, escrita, audiovisual" entre parênteses, e, por essa razão, os consideramos em categorias distintas.

Considerando as categorias de análise que definimos a priori, cada um dos termos foi compreendido em uma categoria de análise distinta, já que estavam evidentemente expressadas. Entretanto, há uma maior compreensão em como as múltiplas linguagens se tornam protagonistas dentro das habilidades propostas na BNCC, nos primeiros anos do ensino fundamental.

A partir dos anos finais percebe-se completa ausência de qualquer menção aos termos que se relacionem com as linguagens escrita e oral, bem como termos/palavras que possam nos elucidar as representações de ordem visual e/ou sonora.

Na sequência trazemos alguns (Figuras 2, 3, 4 e 5), demonstrando de forma objetiva nossos resultados e em seguida abordamos a discussão com referencial teórico, a partir de uma análise dos anos de ensino e unidades temáticas, em casos mais específicos.

Nos anos iniciais, mais especificamente nos 1 으 e 2ㅇ anos (Figura 2), percebe-se o termo "produção de texto" acompanhando uma das exemplificações. Vale salientar o detalhamento entre parênteses dos termos "orais, escritos e audiovisuais", que parecem dialogar com a perspectiva multimodal e de diversas linguagens.

Nesse contexto, cabe estabelecermos um diálogo transversalizado sobre quais unidades temáticas preconizam múltiplas linguagens e produção de textos sob a ótica de uma tentativa multimodal. Destacamos, assim, que esses termos aparecem apenas nas unidades temáticas "brincadeiras e jogos" e "ginásticas".

É importante salientar que estes anos de ensino são os que têm maior variedade de linguagens e representações. Assim, ao serem trabalhadas todas as unidades temáticas propostas, teríamos, em tese, o aprendizado de múltiplas linguagens. Entretanto, cabe a reflexão se o aprendizado estaria se dando de uma forma multimodal.

Para o New London Group, fazer da escola um ambiente multimodal, apropriando-se das mídias digitais e transitando entre diferentes modalidades de linguagem - buscando paralelos e construindo novos sentidos - tornaria a educação mais atraente e forneceria uma base poderosa para mudanças em direção a 


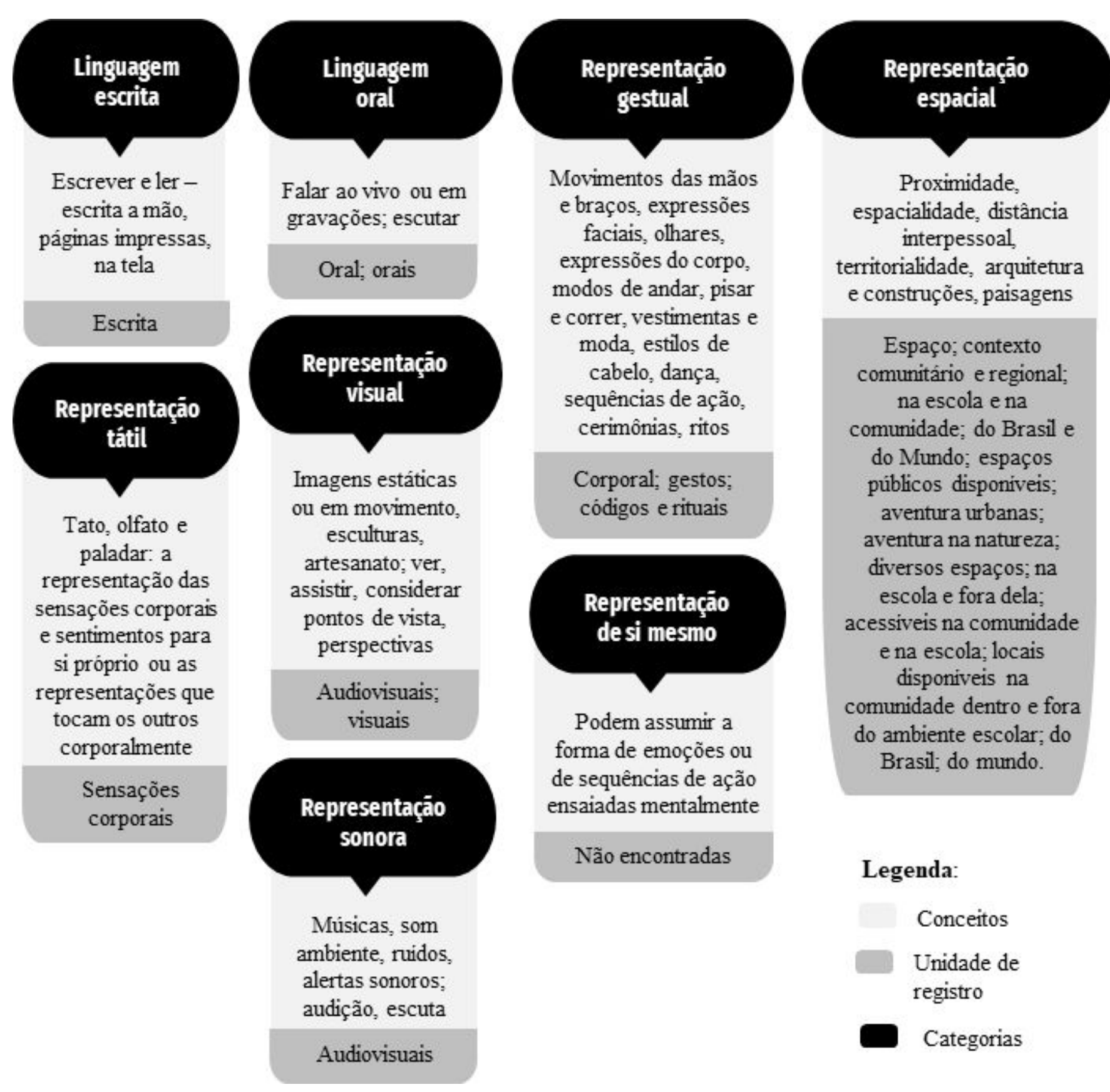

Figura 1. Categorias, conceitos de Cope e Kalantzis (2009) e as unidades de registros encontrados na Educação Física da BNCC. Fonte: Elaborado pelos autores (2021).

uma pedagogia da sinestesia. A multiplicidade não se daria apenas pela presença de diferentes linguagens na educação, mas também pelos diálogos entre/em diferentes linguagens e sentidos, pela capacidade de transitar por elas, de traduzi-las, misturá-las, mixá-las. (Pereira, 2014, p. 93).

Inferimos então, especialmente após a compreensão da multimodalidade, que apesar da linguagem e suas representações serem variadas e por estarem subdivididas em unidades temáticas muito distintas, dificilmente trariam as interconexões e trânsito entre elas.
À revelia do entendimento acerca da necessidade de conectar múltiplas linguagens, de fato percebemos que mesmo no esforço do detalhamento citar as linguagens, não há aprofundamento, complexidade e, pela ausência de mais elementos, infere-se um esgotamento das linguagens preconizadas, especialmente quando se restringem a poucas habilidades, vinculadas a unidades temáticas muito específicas como discutido anteriormente, evidenciado nas próximas Figuras e análises.

Estabelecendo um diálogo transversal, agora com as unidades temáticas, cabe trazer à tona a ausência 


\section{0 e 20 anos}

\section{\begin{tabular}{|c|} 
Oral \\
\hline Linguagem oral
\end{tabular}

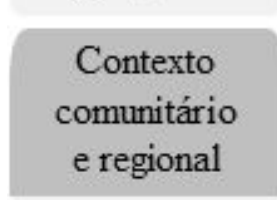

Representação espacial

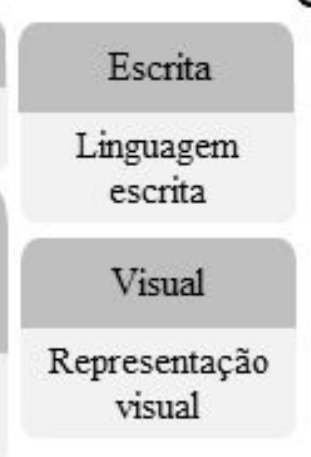

Contexto

Legenda:

Unidade de registro

Categorias

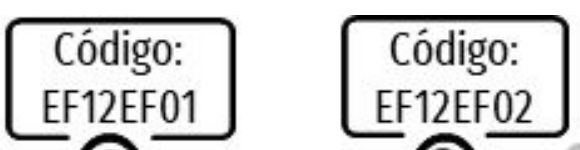

EF12EF01 EF12EF02

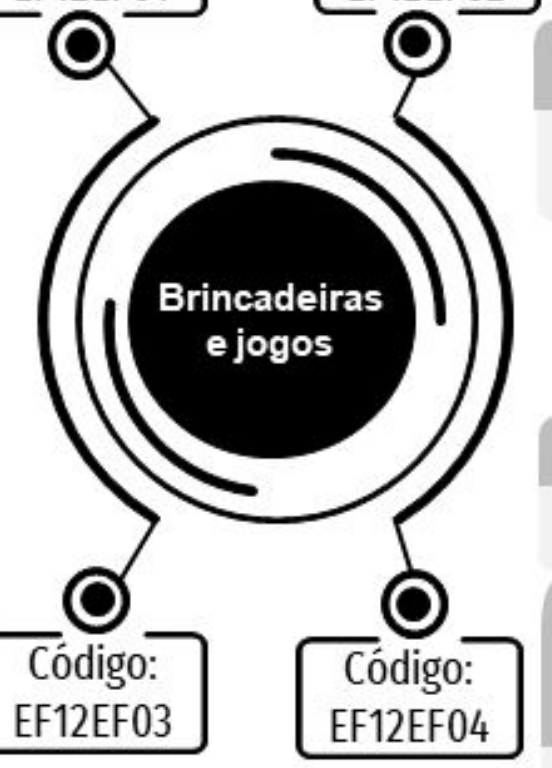

Corporal

Representação gestual
Contexto e regional

Representação espacial comunitário

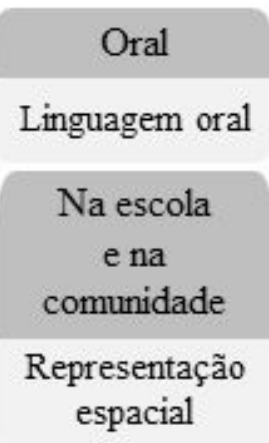

\section{Escrita \\ Linguagem escrita \\ Audiovisuais \\ Representações sonora e visual}

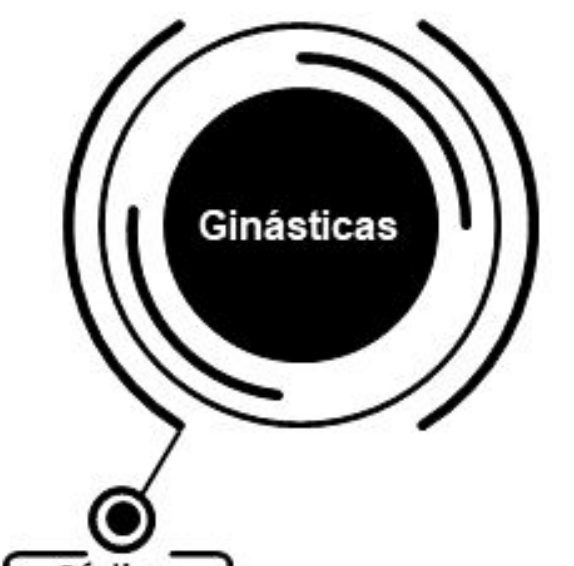

Código: EF12EF10

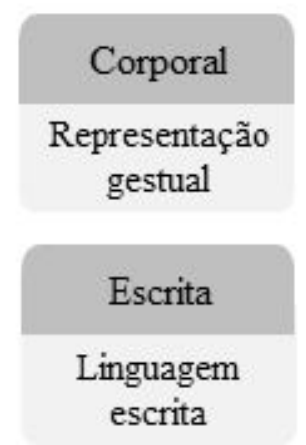

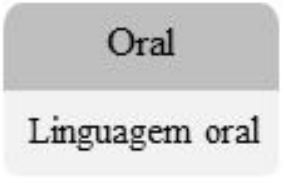

Audiovisual

Representações sonora e visual

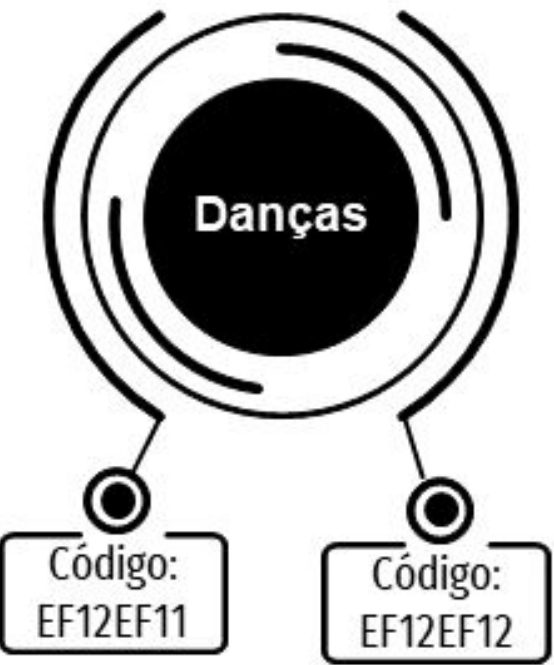

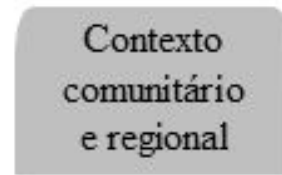

Representação espacial

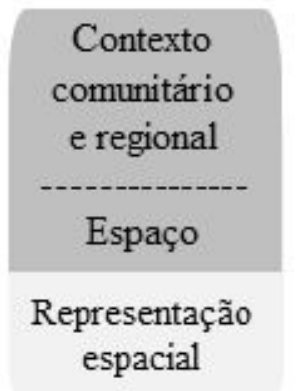

\section{Gestos}

Representação gestual

Figura 2. Unidades de registro e categorias do 1 으 e 2ㅇaㅇ por unidades temáticas e habilidade. Fonte: Elaborado pelos autores (2021).

completa de unidades de registro (conforme pode-se observar nos Figuras 2 e 3 ) que acarretem relações com a unidade temática "esportes". Nesse ponto resgatamos
Marchi (2014, p. 194), quando nos diz que "tendo em vista que o desporto muda e amplia incessantemente o seu significado, tanto no que se refere a uma atitude 

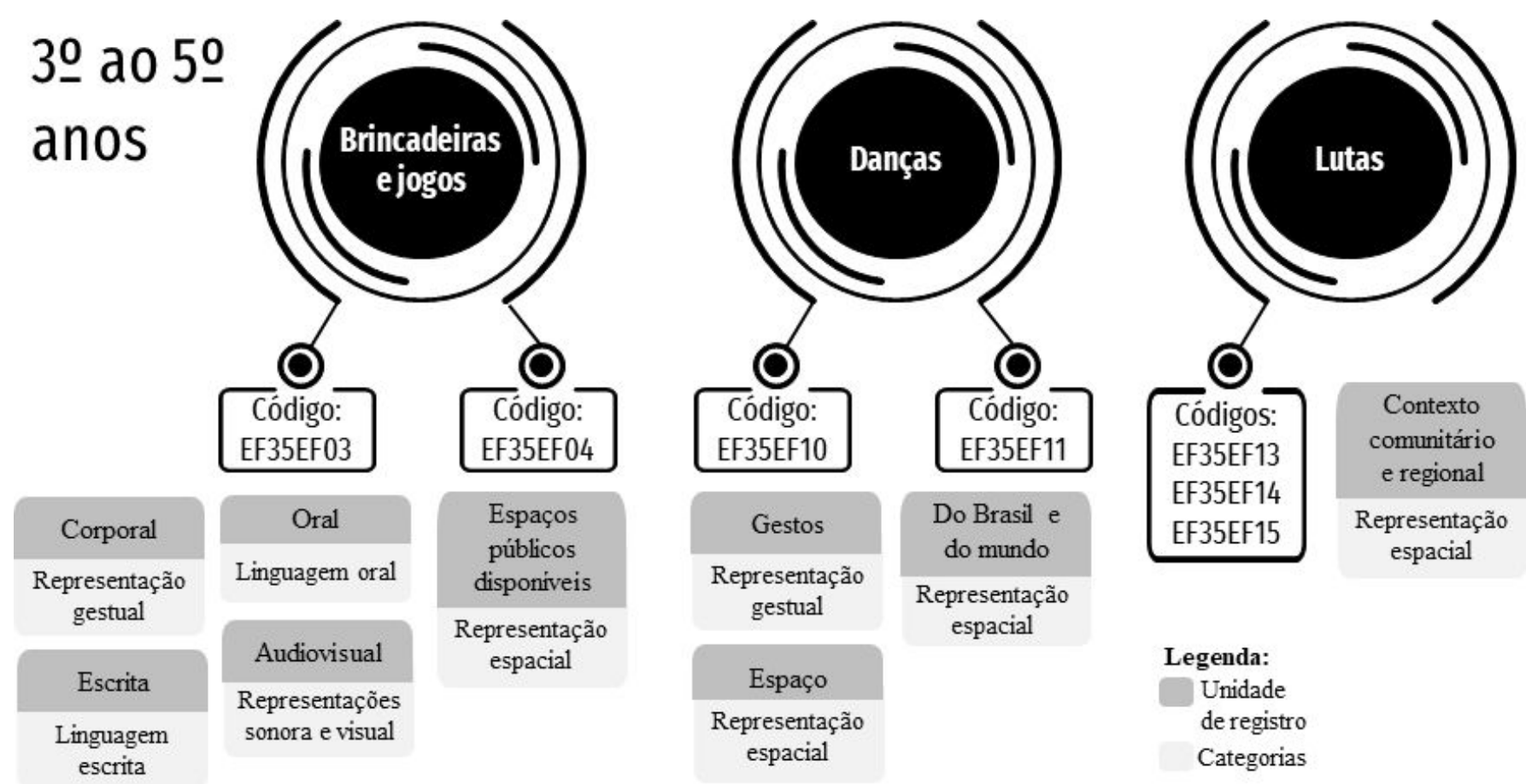

Figura 3. Unidades de registro e categorias do 3으 a 5 ano por unidades temáticas e habilidade. Fonte: Elaborado pelos autores (2021).

e atividade humana quanto ao entendimento de uma realidade social complexa". Para refletir e problematizar, que diante de um fenômeno polissêmico e multifacetado como o esporte, torna-se preocupante que as linguagens e suas representações estejam ausentes das habilidades preconizadas por este documento que referenda a Base dos conhecimentos comuns a todo cidadão e cidadã do Brasil.

Concluindo a análise dos anos iniciais do ensino fundamental, a apreciação das Figuras nos demonstra a ausência de unidades de registro que possam ser atribuídas às categorias: representação sonora (de forma individualizada), representação de si, assim como representação tátil.

Conforme os conceitos trazidos para elucidar nossas categorias de análise (Figura 1) e considerando que a Educação Física deve preconizar as experiências com práticas corporais numa perspectiva de conhecimento de si e da linguagem, que é vista como expressão do ser no mundo. Problematizamos esse resultado significativo pela ausência, a partir do entendimento de que "[...] as práticas corporais disponibilizam significações capazes de operar sínteses provisórias e de reduplicar o conhecimento sobre o corpo em áreas como a Educação Física" (Nóbrega e Medeiros, 2009, p, 728), o que não pudemos observar, inferir ou constatar, qualquer mínima relação.

Iniciando nossa análise dos anos finais do ensino fundamental com a Figura das categorias do 6ㅇ e 7으 anos (Figura 4), em que percebemos uma transição entre as linguagens e representações preconizadas. Nota-se que há apenas menções à perspectiva das representações gestuais (com pouca recorrência) e das representações espaciais (em maior recorrência se considerarmos as unidades de registro que se unem em uma só categoria), em especial na unidade temática "ginásticas", que a posteriori se esvazia. Estão completamente ausentes as linguagens oral e escrita.

Neste ponto, destacamos que há apenas uma única menção às representações táteis em todas as habilidades propostas, representada pelo termo "sensações corporais" na unidade temática "ginásticas", em que se tematizam as ginásticas de conscientização corporal e, onde acreditamos, poderia ser um rico campo de experiências com as linguagens.

Percebe-se na leitura das habilidades propostas para esta unidade temática, uma tendência a considerar aspectos restritivamente ligados às capacidades físicas. No sentido exatamente oposto, concordamos com Pereira (2014, p. 93) que,

[...] ao invés de restringirem o corpo e o movimento humano a conteúdos abordados pela biologia ou pela biomecânica, os multiletramentos trazem a dimensão corporal para as discussões linguísticas, delimitando, dentre as modalidades de linguagem sugeridas para o trabalho pedagógico, as representações gestuais e as representações táteis (sensitivas). Assim, não evocam um corpo metafísico, reificado, mas um corpo sensível, simbólico, dialógico. Corpo que é condição para o ser e o estar no mundo.

No rastro dessa reflexão e de uma compreensão de linguagem que considere efetivamente o corpo e sua sensibilidade, assim como nos aponta Santos e Fuzii (2019, 


\section{6으 e 7으 anos}

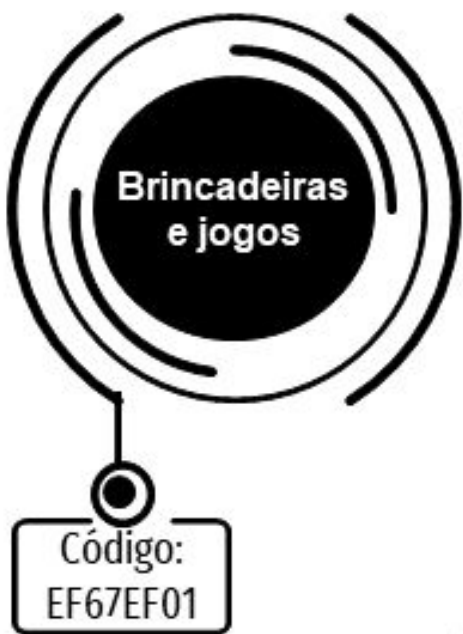

\section{$\mathrm{Na}$ escola e fora dela}

Representação espacial

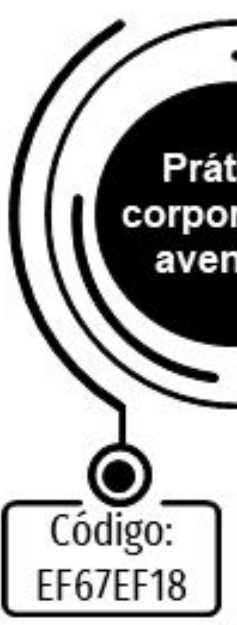

Aventura urbana

Representação espacial
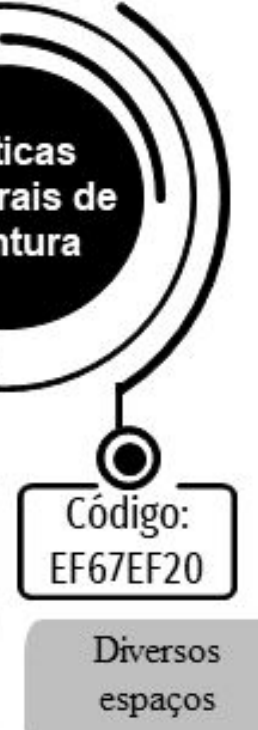

Representação espacial
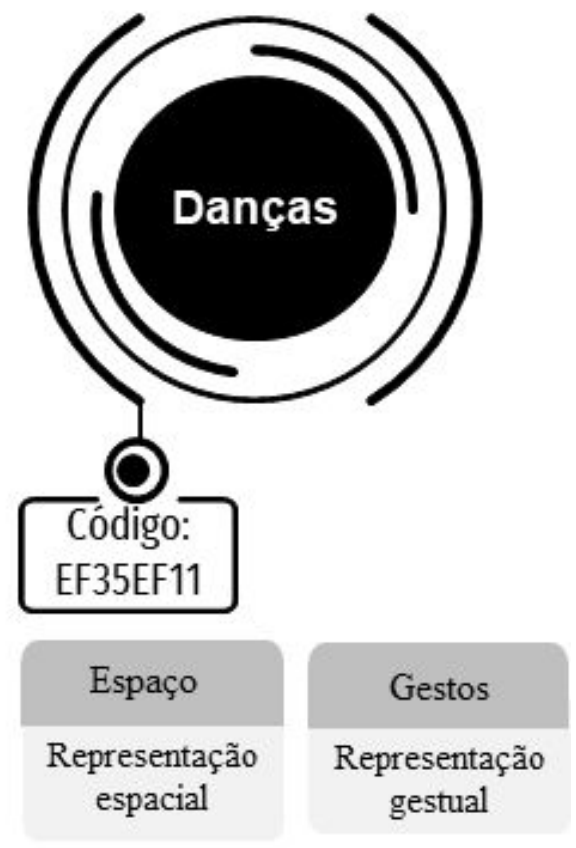

\section{Sensações corporais}

Representação tátil

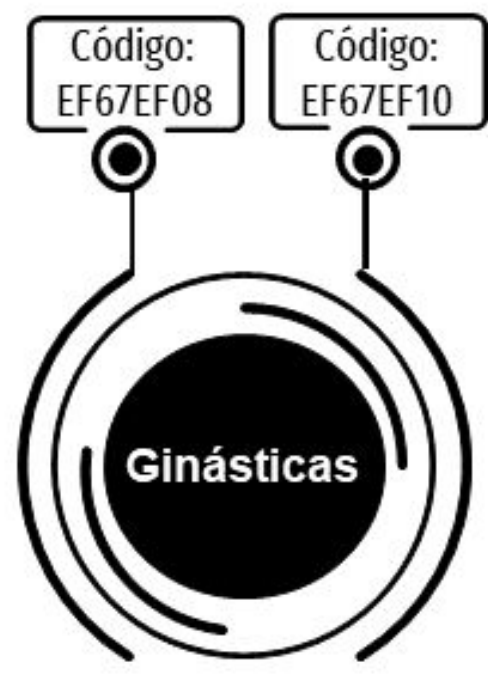
espacial

\section{Dentro e fora do ambiente escolar}

Representação

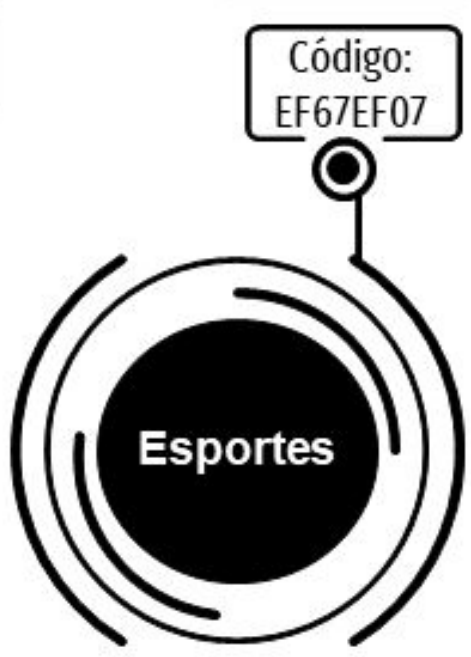

\section{Acessiveis} na escola e fora dela

Representação espacial

Unidade de registro

\section{Legenda:}

\section{Do Brasil}

Representação
espacial

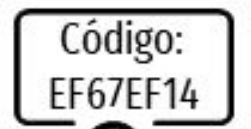

\section{Códigos e rituais \\ Representação gestual}

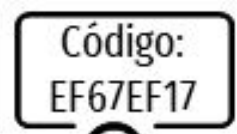

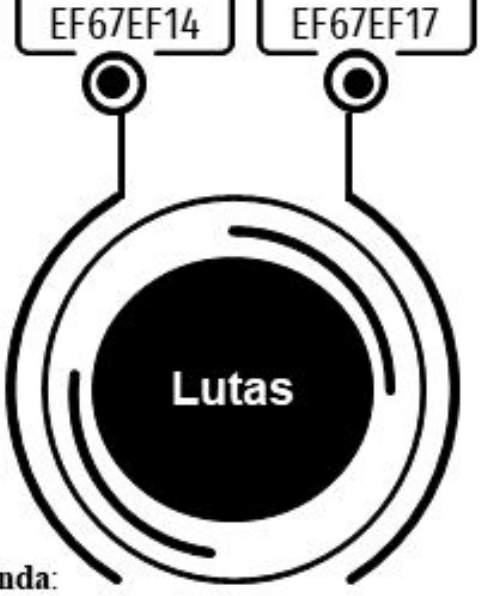

Categorias

Figura 4. Unidades de registro e categorias do 6ㅇ e 7으 ano por unidades temáticas e habilidade. Fonte: Elaborado pelos autores (2021).

p. 327) ao relatar o percurso histórico pelo qual passou a Educação Física até chegar a área das linguagens, nos diz que "a Educação Física compreendida como linguagem rompe com as barreiras impostas pelo histórico da área pautado unicamente no caráter biológico e passa então a dar um entendimento mais abrangente sobre o corpo", ou pelo menos deveria, pois as inferências que trazemos é que essa perspectiva de corpo, linguagem e habilidades está no sentido oposto. Percebemos, então, grande limitação e, por que não dizer, visão limítrofe das 


\section{8ㅇ e 90 anos}

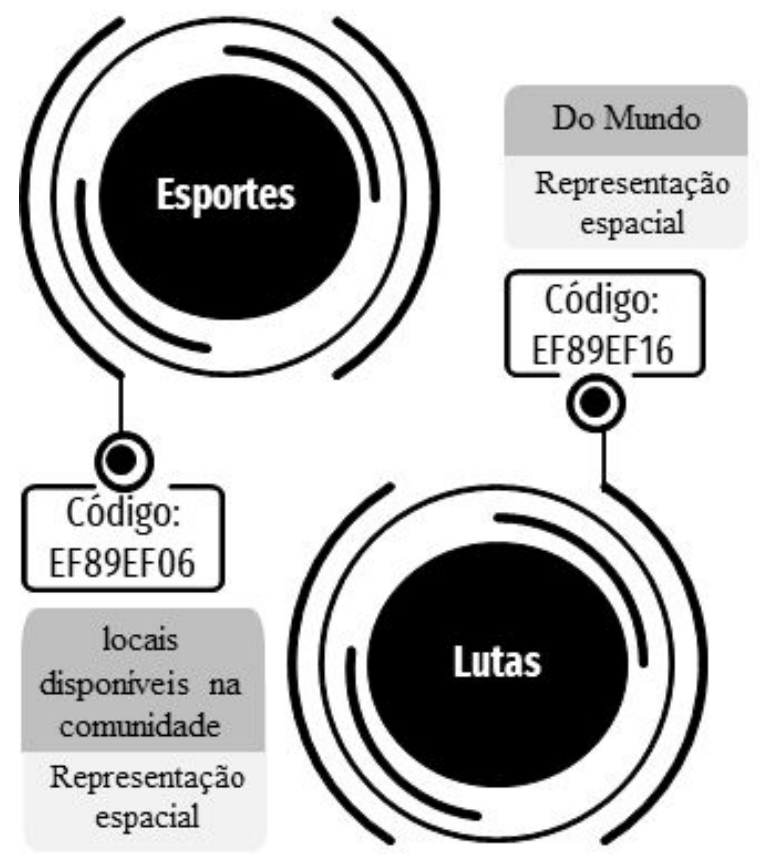

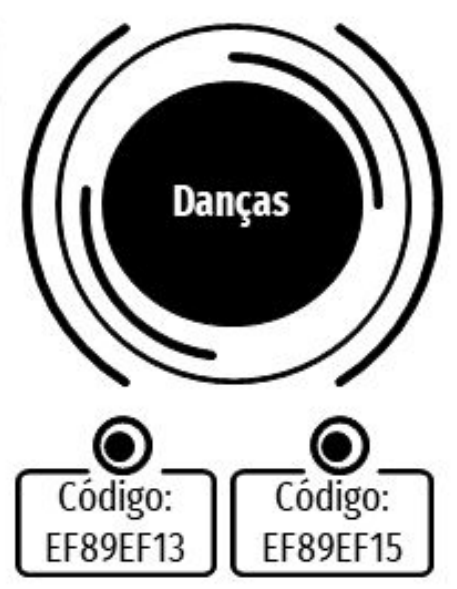

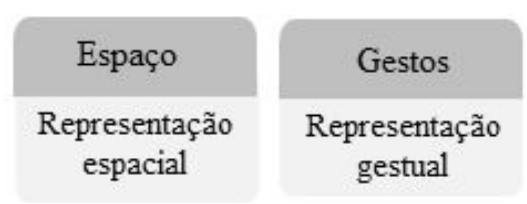

Legenda:

Unidade Categorias de registro

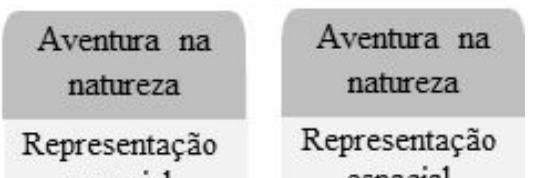
espacial

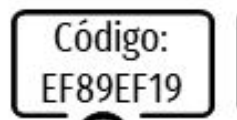
espacial

\section{Código: EF89EF20}

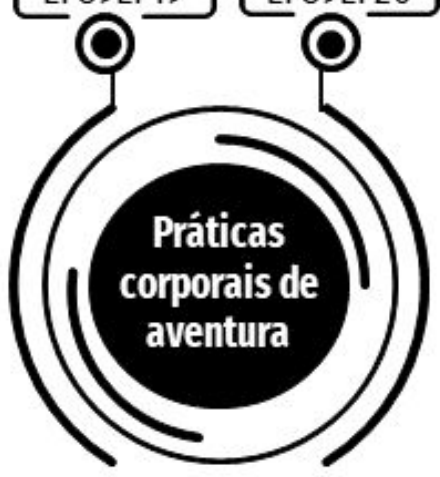

Figura 5. Unidades de registro e categorias do 8 e 9 ano por unidades temáticas e habilidade. Fonte: Elaborado pelos autores (2021).

possibilidades expressivas das linguagens e um retorno ao que foi preconizado e extensivamente discutido ao longo dos anos 90 (Santos e Fuzii, 2019).

Também como representante único da categoria "representação gestual", trazemos a unidade temática "lutas", que enfatiza seu potencial de compreensão de códigos e rituais apenas nos 6ㅇ e 7ㅇ anos, embora essa unidade temática esteja ausente nos 1 으 e 2 으osos.

Assim, cabe-nos problematizar o tempo pedagógico para compreensão de códigos e rituais comuns às lutas, quando esta habilidade está restrita a apenas dois anos de ensino. Gomes et al. (2013, p. 310) apresenta as possibilidades de conhecimentos que a unidade temática lutas pode viabilizar no processo de ensino-aprendizagem e ratifica sua importância na escola quando dizem que:

Ao conhecer as lutas em diversos aspectos (políticos, econômicos, sociais, históricos, estéticos, fisiológicos etc.), os alunos poderão se apropriar de elementos que contribuirão coma construção crítica de conhecimentos, valores, atitudes, fatos e procedimentos que auxiliarão na ampliação de suas visões de mundo.

Para tanto, acrescentamos que restringir as lutas a categoria espacial é minimizá-las enquanto potência educativa, pois se for planejada de forma que amplie as experiências comunicativas e de expressão, como é proposto na perspectiva dos multiletramentos, este conteúdo de ensino torna-se ainda mais significativo.

Dessa forma, infere-se que linguagens que são tradicionalmente exploradas no processo de escolarização (por exemplo linguagens oral e escrita) não são preconizadas nos anos finais do ensino fundamental, muito menos uma perspectiva multimodal que, para tanto, materializar-se-ia no

\section{[...] proposto que as representações multimodais da linguagem, potencializadas e mixadas nas mídias e tecnologias digitais, sejam inseridas em sala de aula e façam parte das produções de sentido e aprendizagens das crianças. Assim, os modos de significação da linguagem escrita estariam cada vez mais em interface com padrões e significações de outras modalidades de linguagem. (Pereira, 2014, p. 91).}

Outro ponto importante que elucida o quanto a diversidade de linguagens e representações são diminutas nos anos finais é a retirada da unidade temática "brincadeiras e jogos", que nos anos iniciais foram responsáveis em grande medida pela ampliação das possibilidades de experimentação da linguagem e suas representações e que nos anos finais, sem a presença dessa unidade temática, se restringem à representação espacial e gestual.

Retomando a unidade temática "esportes", que é tradicional no ensino da Educação Física, percebemos que nos anos finais sua relação acontece apenas com a categoria de representação espacial.

O severo empobrecimento da compreensão de esporte enquanto um fenômeno polissêmico e, portanto, carregado de linguagens, o que nos faz questionar fortemente se não haveria aspectos da linguagem e suas representações que pudessem ser contemplados e protagonizados nesta unidade temática. 
Considerando ainda unidades temáticas que estão presentes em todos os anos de ensino, dialogamos neste instante com as "danças", as quais aparecem apenas duas representações nas unidades de registro, a saber: gestual e de espaço. Nossa crítica neste ponto se estabelece mais uma vez no esvaziamento do seu potencial de exploração da linguagem, inclusive pelas próprias noções do gesto como linguagem, como argumentaram Laban (1990), Nóbrega e Medeiros (2009). Nesse sentido, a dança é atravessada por significações que podem ampliar outras habilidades que expressam linguagens, como destaca Laban (1990, p. 32) ao afirmar que "[...] assim como as palavras são formadas por letras, os movimentos são formados por elementos; assim como as orações são compostas de palavras, as frases da dança são compostas de movimento".

É necessário destacar a única unidade temática que está presente apenas nos anos finais do ensino fundamental: "práticas corporais de aventura", que se restringem exclusivamente a abordar a categoria representação espacial (Figura 4 e 5). No rastro dessa recorrência, trazemos também uma reflexão sobre o seu potencial de linguagens e representações, conforme nos aponta Machado (2006, p. 107).

[...] o elemento natureza, ambiente das atividades de aventura, pode possibilitar enriquecimento das habilidades sensíveis e emocionais, uma vez que proporciona maior interação entre o ser humano e o meio natural; valorizando a percepção por meio do desenvolvimento das potencialidades táteis, auditivas e olfativas, proporcionando sensação de pertencimento a algo grande e coletivo, o que requer senso de responsabilidade e afetividade com o todo. Isto difere sensivelmente do cotidiano urbano, onde se destaca, principalmente, a habilidade visual e, consequentemente, o distanciamento, a agilidade e o individualismo.

A revelia de todo potencial já descrito na literatura, exemplificado no argumento acima, percebemos justamente uma limitação à representação espacial e ainda bem limitadas na polaridade natureza $\mathrm{x}$ urbano, apresentadas como possibilidades espaciais excludentes.

No rastro dessa reflexão, concordamos com Severino et al. (2016, p. 122) quando elucida que na área de estudos sobre aventura "[...] acredita-se que o conceito de natureza não deve ser uma simples oposição à ideia de urbanidade, pois sua etimologia vai além desta noção". Assim sendo, infere-se que tanto a unidade temática minimamente explorada em seu potencial expressivo, quanto o pouco que é explorado, acaba tornando-se reducionista para além da maior limitação de estar restrita apenas aos anos finais.

Do primeiro (10 e 20 anos) ao quarto bloco ( 8 e e 9o anos) da etapa do Ensino Fundamental, destacou-se um desinvestimento na quantidade e multiplicidade de linguagens acionadas pelas habilidades da Educação
Física. Foram vinte e uma menções no primeiro bloco, correspondendo à ocorrência de seis possibilidades de expressão de linguagem. Enquanto que no quarto bloco, sete menções foram explicitadas, dentre as quais somente duas expressões de linguagens foram acionadas.

Em articulação com esse desinvestimento no decorrer desses blocos, destacamos a concentração de ocorrências de linguagens nas habilidades vinculadas a três unidades temáticas: (a) Brincadeiras e Jogos; (b) Ginásticas; e (c) Danças. As "Brincadeiras e Jogos" apresentam o maior quantitativo de ocorrências e multiplicidade de linguagens no decorrer dos blocos de ensino, mesmo sendo desconsiderado pela BNCC nos anos finais dessa etapa de ensino. Somente a representação de si mesmo e a representação tátil que não foram mencionadas nas habilidades da unidade de "Brincadeiras e Jogos".

As representações de si mesmo não apareceram em nenhum momento da análise, diferentemente da representação tátil, que se configurou na unidade temática de "Ginásticas". Essa unidade, nos dois primeiros blocos de ensino, apresenta uma multiplicidade de linguagens em suas habilidades, o que não ocorre nos últimos blocos. As "Danças", diferentemente das unidades anteriores, se destaca somente pelas ocorrências quantitativas de expressões de linguagens, estando restrita à representação gestual e espacial, semelhante a unidade temática das "Lutas", porém, com menor ocorrência. As "Práticas Corporais de Aventura", por sua vez, apresenta a representação espacial como possibilidades, também com poucas ocorrências.

No entanto, é na unidade temática "Esportes" que identificamos o argumento mais significativo quanto à fragilidade da presença das linguagens nas habilidades da Educação Física na perspectiva do ensino fundamental. Essa unidade está presente em todo percurso desta etapa de ensino, apresentando o maior quantitativo de proposições de habilidades ao mesmo tempo que apresenta a menor ocorrência numérica de expressões de linguagens, sendo duas representações espaciais nos 8 e 9 o anos do fundamental.

Por fim, a BNCC como documento que orienta as aprendizagens essenciais dos(as) alunos(as) ao longo da trajetória escolar apresenta, ainda que de forma fragilizada e intimista, indicativos de múltiplas linguagens. No entanto, como resultados das nossas análises, denotamos a importância de considerar uma aprendizagem pautada na experiência de linguagens múltiplas e sensíveis.

\section{CONSIDERAÇÕES FINAIS}

A análise realizada fortalece a evidência da limitada proposição da BNCC para com a riqueza de possibilidades exploradas pela Educação Física dentro da área do conhecimento de linguagens. Destacamos, no entanto, o reconhecimento de um investimento teórico de aproximações dessas áreas em uma perspectiva 
multimodal, que reconhece as múltiplas possibilidades de letramento como uso social da linguagem. Essa literatura, porém, não sustentou ou mesmo demonstrou-se reconhecida na sessão do componente curricular de Educação Física da BNCC. Assim, além de uma argumentação teórica efêmera sobre a linguagem, evidenciou-se a sua marginalidade em relação às habilidades propostas no decorrer dos anos da etapa do Ensino Fundamental.

Dessa forma, entendemos que a presença das linguagens nas habilidades propostas pela BNCC para o componente curricular de Educação Física é insatisfatória, diante dos horizontes de possibilidades para as diferentes unidades temáticas que uma concepção de linguagem com sólida fundamentação teórica pode viabilizar. Ressaltamos, no entanto, o reconhecimento das possíveis limitações da nossa análise, na qual destacamos a opção de assumir categorias de análise a priori.

Percebemos então, como possível contribuição do nosso trabalho, apontar a fragilidade da presença da linguagem nas habilidades da Educação Física, trazendo elementos que ratifiquem a necessidade das formações iniciais e continuadas dos professores e na construção dos currículos e projetos escolares dos Estados e Municípios que possam contemplar esse hiato presente na BNCC.

\section{FINANCIAMENTO}

O presente trabalho foi realizado com apoio da Coordenação de Aperfeiçoamento de Pessoal de Nível Superior - Brasil (CAPES) - Código de Financiamento 001.

\section{CONFLITOS DE INTERESSE}

Os autores declaram não haver conflito de interesse.

\section{REFERÊNCIAS}

Bardin, L. Análise de conteúdo. São Paulo: Edições 70; 2011.

Brasil. Ministério da Educação. Parâmetros Curriculares Nacionais [Internet]. Brasília: MEC; 1997 [citado 2021 Mar 9]. Disponível em: http://portal.mec.gov.br/seb/arquivos/ pdf/livro07.pdf

Brasil. Ministério da Educação. Base Nacional Comum Curricular [Internet]. Brasília: MEC; 2018 [citado 2021 Mar 9]. Disponível em: http://basenacionalcomum.mec. gov.br/images/BNCC_El_EF_110518_versaofinal_site.pdf

Cope B, Kalantzis M. "Multiliteracies": new literacies, new learning. Pedagogies. 2009;4(3):164-95. http://dx.doi. org/10.1080/15544800903076044.
Furlan R, Bocchi JC. O corpo como expressão e linguagem em Merleau-Ponty. Estud Psicol. 2003;8(3):445-50. http:// dx.doi.org/10.1590/S1413-294X2003000300011.

Gomes NC, Barros AM, Freitas FPR, Darido SC, Rufino LGB. O conteúdo das lutas nas séries iniciais do ensino fundamental: possibilidades para a prática pedagógica da educação física escolar. Motrivivência. 2013;(41):305-20. http://dx.doi.org/10.5007/2175-8042.2013v25n41p305.

Kunz E. Educação Física: ensino \& mudanças. ljuí: Unijuí; 1991. Laban R. Dança educativa moderna. São Paulo: Ícone; 1990.

Machado FH. Mundo emocionado e as atividades física de aventura na natureza. In: Schwartz GM, editor. Aventuras na natureza: consolidando significados. Jundiaí: Fontoura; 2006.

Marchi W Jr. Desporto. In: González FJ, Fensterseifer PE.editores. Dicionário crítico de Educação Física. 3. ed. Ijuí: Unijuí; 2014. p. 192-6.

Merleau-Ponty M. Signos. São Paulo: Martins Fontes; 1991.

Minayo MCS. O desafio do conhecimento: pesquisa qualitativa em saúde. 10. ed. São Paulo: HUCITEC; 2007.

Neira MG. Incoerências e inconsistências da BNCC de Educação Física. Rev Bras Ciênc Esporte. 2018;40(3):215-23. http:// dx.doi.org/10.1016/j.rbce.2018.04.001.

Nóbrega TP, Medeiros RMN. A palavra é gesto: reflexões estéticas sobre o corpo. Motriz [Internet]. 2009 [citado 2021 Fev 20];15(3):723-8. Disponível em: https://www. periodicos.rc.biblioteca.unesp.br/index.php/motriz/ article/view/2322/2542

Pereira RS. Multiletramentos, tecnologias digitais e os lugares do corpo na Educação [tese]. Florianópolis: Centro da Ciência da Educação, Universidade Federal de Santa Catarina; 2014 [citado 2021 Mar 10]. Disponível em: https://repositorio. ufsc.br/xmlui/handle/123456789/123332

Rosa, BB. A transdisciplinaridade das Literacias Emergentes no Contemporâneo Conectado: um mapeamento do universo documental das Literacias de Mídia e Informação (MIL) [dissertação]. São Paulo: Escola de Comunicações e Artes da Universidade de São Paulo; 2016 [citado 2021 Mar 17]. Disponível em: https://www.teses.usp.br/teses/ disponiveis/27/27154/tde-09032017-143021/pt-br.php

Santos BCA, Fuzii FT. A Educação Física na área da linguagem: o impacto da BNCC no currículo escolar. Comunicações. 2019;26(1):327-47. http://dx.doi.org/10.15600/2238121X/comunicacoes.v26n1p327-347.

Severino AJ, Pereira DW, Santos VFS. Aventura e educação na Base Nacional Comum. Eccos. 2016;41(41):107-25. http:// dx.doi.org/10.5585/eccos.n41.6954. 